\title{
INSERINDO O CONCEITO LIXO ZERO E A ECONOMIA SUSTENTÁVEL EM ESCOLAS PÚBLICAS DE FLORIANÓPOLIS
}

Thiago Teixeira Mendonça Universidade Federal de Santa Catarina thiagomendonca26@gmail.com

Marilia Dietrich Schmitz Universidade Federal de Santa Catarina marilia.d.schmitz@gmail.com

Isabela Tsutiya Andrade Universidade Federal de Santa Catarina isa.t.andrade@gmail.com

Resumo

O presente projeto iniciado em 2016, teve como objetivo a realização da semana Lixo Zero em uma escola de ensino básico de uma região de baixa renda na cidade de Florianópolis, a Escola Básica Municipal Donícia Maria da Costa. Em 2017, o projeto foi continuado com práticas de educação ambiental focadas nos conceitos Lixo Zero e Economia Circular e Solidária. Essas práticas, realizadas através de atividades conjuntas, incluem oficinas, construção de composteira, debates, questionários, mostras de filme, etc. O trabalho de educação ambiental teve resultados muito positivos, uma vez que toda a comunidade próxima foi atingida e as crianças do coletivo conseguiram gerar renda (economia solidária) a partir de uma feira, onde foram vendidos objetos elaborados pelos próprios participantes, nas oficinas. $\mathrm{O}$ projeto continua sendo aplicado em 2018, com objetivo principal de ajudar na instituição da Educação Ambiental no Plano Político Pedagógico.

Palavras-chave: Educação Ambiental. Pedagogia. Meio Ambiente.

\section{INTRODUCING ZERO WASTE CONCEPT AND SUSTAINABLE ECONOMY IN PUBLIC SCHOOLS IN FLORIANÓPOLIS}

\begin{abstract}
The project presented, initiated in 2016, had an objective to hold a Zero Waste Week at a low-income elementary school in Florianópolis. In 2017 the project continued through Environmental Education practices focused on concepts such as Zero Waste and Circular and Solidarity Economy. These practices included interactive workshops, the construction of a compost bed, debates, questionnaires, films and so on. These approaches had a number of positive results. The nearby community benefited through education and the Zero Waste Collective members managed to generate income (Solidarity Economy) from a market stall set up on the street. The products sold were created by the handwork of the children who took part in the workshops. The project remains in progress currently, however with a different purpose: institute Environmental Education guidelines in the Pedagogical Political Plan.

Keywords: Environmental Education. Pedagogy. Environment.

\section{INSERCIÓN DEL CONCEPTO BASURA CERO Y ECONOMÍA SOSTENIBLE EN ESCUELAS PÚBLICAS DE FLORIANÓPOLIS}

\section{Resumen}

El proyecto trata de la continuación de otro, iniciado en 2016, que tuvo como objetivo la realización de la semana Basura Cero en una escuela de enseñanza básica de una región de bajos ingresos en la ciudad de Florianópolis, la Escuela Básica Municipal Donícia Maria da Costa. En 2017, el proyecto el proyecto se continuó a través de prácticas de educación ambiental con foco en los conceptos Basura Cero y Economía Circular y Solidaria. Estas prácticas, realizadas a través de actividades conjuntas, incluyen talleres, construcción de compostela, debates, cuestionarios, exhibición de películas, etc. El trabajo de educación ambiental tuvo resultados muy positivos, una vez que toda la comunidad cercana fue contemplada y los niños involucrados lograron generar ingresos (economía solidaria) a partir de una feria donde se vendieron objetos elaborados por ellos mismos en los talleres. El proyecto sigue siendo aplicado en 2018, con el objetivo principal de ayudar con la implementación de Educación Ambiental en el Plan Político Pedagógico.

Palavras clave: Educación Ambiental. Pedagogía. Medio Ambiente. 
Inserindo o conceito lixo zero e a economia sustentável em escolas públicas de Florianópolis

\section{O PROJETO ONTEM E HOJE}

A problemática dos resíduos sólidos no Brasil segue alarmante, face à sua crescente geração (ABRELPE, 2015) que, além dos impactos no ambiente e saúde pública, representam um enorme desperdício econômico. Questões econômicas e de desigualdade social são um dos fatores que dificultam a implementação da gestão de resíduos em países em desenvolvimento (MARSHALL; FARAHBAKHSH, 2013; WILSON, 2007) visto que, em situações de pobreza, as questões associadas às necessidades de sobrevivência superam aquelas relacionadas ao meio ambiente.

Os conceitos de Economia Solidária, Economia Circular e Lixo Zero são utilizados, conjuntamente, neste contexto, como base teórica para transformação nas problemáticas sociais e dos resíduos, assim como o desenvolvimento sustentável. Lixo Zero atua através de práticas e incentivos que objetivam o máximo reaproveitamento e correto encaminhamento dos resíduos recicláveis e orgânicos, diminuindo assim a quantidade de rejeito encaminhado para o aterro sanitário (INSTITUTO LIXO ZERO BRASIL, 2018).

Economia solidária é, segundo Razeto (1997), uma maneira de se chegar a uma estrutura de sociedade em que suas bases são os valores de solidariedade, através do apoio à cultura e às necessidades locais. A economia circular é um contraponto ao modelo linear de produção. $\mathrm{O}$ modelo linear, usual, é tido como insustentável, visto que trata o caminho dos recursos com unilateralidade, desde a produção até o descarte. O modelo circular prevê o reaproveitamento dos materiais, bem como a redução de impactos ambientais (ELLEN MACARTHUR FOUNDATION, 2017)

O Desafio Lixo Zero foi aplicado pela primeira vez em 2015 no Colégio de Aplicação (CA) da UFSC, no âmbito do trabalho de conclusão de curso do, hoje, engenheiro e mestre Luiz Gabriel Catoira de Vasconcelos, e desenvolvido em parceria com o Núcleo de Educação Ambiental da UFSC (NEAmb). A metodologia proposta para aplicação deste conceito trouxe resultados positivos para o Colégio, dentre os quais, a redução em $50 \%$ na quantidade de resíduos sólidos, enviados diariamente ao aterro sanitário; novas experiências e desenvolvimento de atividades pedagógicas voltadas ao tema; e a integração de servidores técnicos, docentes, alunos e familiares por meio da formação de grupos de trabalho, como o Coletivo Lixo Zero (VASCONCELOS, 2015).

Em 2016, o projeto "Lixo Zero: o Colégio de Aplicação da UFSC como unidade demonstrativa de boas práticas em gestão de resíduos sólidos", buscou incentivar a adoção de práticas de Educação Ambiental. Além do CA, a metodologia foi aplicada em duas outras escolas: 
Inserindo o conceito lixo zero e a economia sustentável em escolas públicas de Florianópolis

Escola Básica Vitor Miguel de Souza e Escola Básica Municipal Donícia Maria da Costa. No final daquele ano, em uma semana voltada à temática do Lixo Zero, foi lançado um desafio às escolas: ficar uma semana sem gerar lixo. Como forma de avaliar os resultados, foram pesados todos os resíduos produzidos ao longo desta semana e comparado com a produção de resíduos de outros períodos.

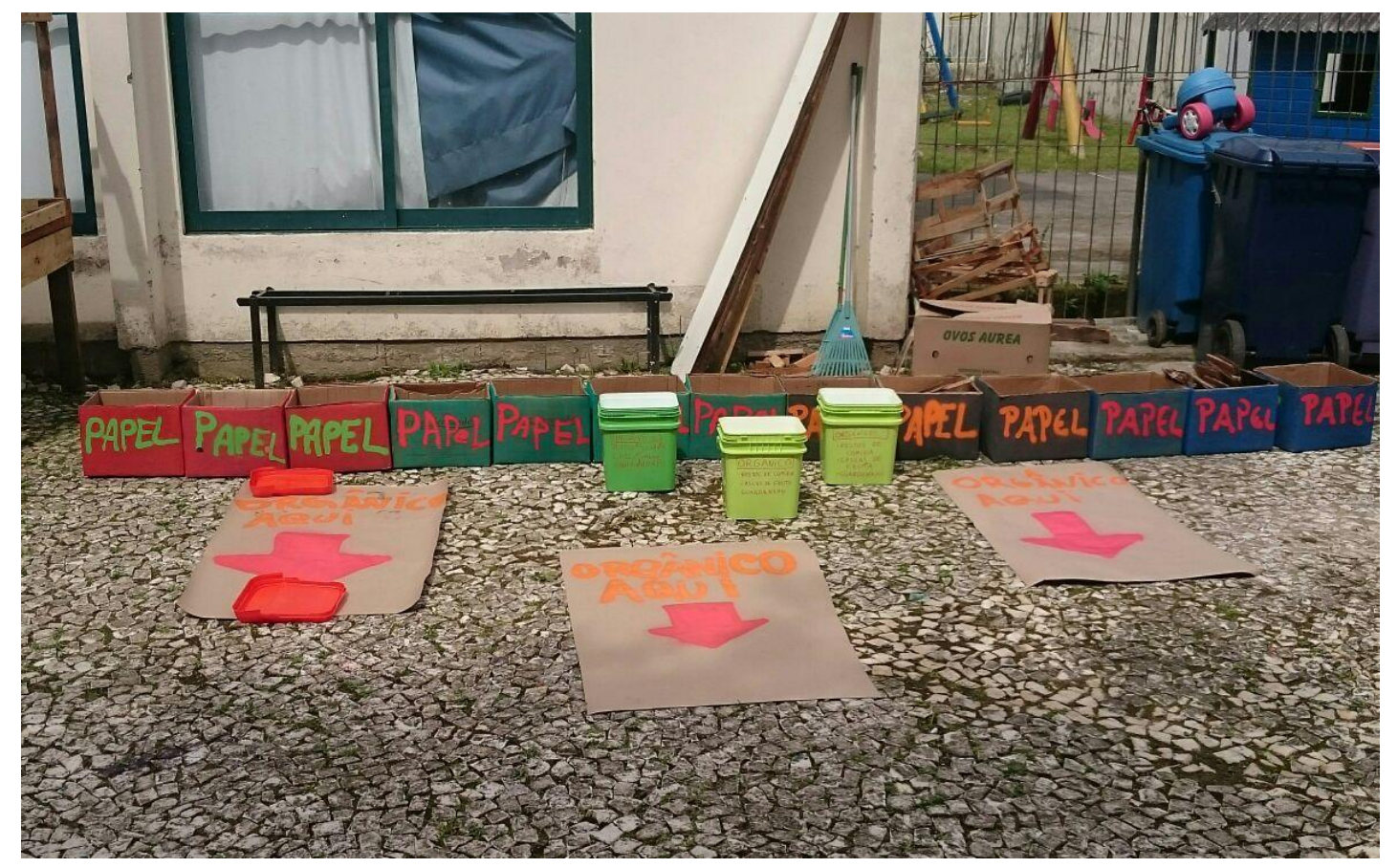

Figura 1 - Preparação para a Semana Lixo Zero de 2016.

Fonte: Registrado pelos autores, 2016.

Como resultado, em 2017 o projeto, "Promovendo a economia circular e solidária a partir do conceito Lixo Zero", foi desenvolvido, com apoio do NEAmb, na escola Donícia, como uma continuação do projeto anterior. O objetivo, nesta nova fase, consistiu em realizar encontros semanais com o Coletivo Lixo Zero, grupo de alunos formado no ano de 2016.

Os encontros eram realizados para discutir os temas relativos aos resíduos, bem como organizar e concretizar oficinas, mutirões e outros eventos relacionados à Economia Circular e Solidária e ao conceito Lixo Zero.

Este artigo apresenta um relato das experiências do grupo de alunos e orientador com a prática de Educação Ambiental em escolas, discutindo as atividades desenvolvidas, bem como as dificuldades enfrentadas e os resultados alcançados. Na condução do projeto "Promovendo a economia circular e solidária a partir do conceito Lixo Zero", alguns métodos utilizados trouxeram resultados positivos, e estes serão descritos neste trabalho. 
Inserindo o conceito lixo zero e a economia sustentável em escolas públicas de Florianópolis

\section{METODOLOGIAS DE AÇÃO}

A equipe de extensionistas que compõe o projeto faz parte do NEAmb da UFSC, um grupo autogestionado por alunos engajados com a extensão universitária e que atua há 10 anos na Universidade e comunidade externa. Os integrantes trabalham em conjunto, a partir de uma metodologia transdisciplinar, de modo que suas vivências prévias são levadas em consideração no desenvolvimento de atividades e resolução de conflitos. Há, também, o acompanhamento teórico-metodológico da professora orientadora, de grande importância para o direcionamento do projeto.

Dentre as atividades realizadas com o coletivo de crianças da escola, a grande maioria teve início a partir da formulação própria de ideias, de forma que se procurou sempre trabalhar com o questionamento para possibilitar uma construção conjunta. Este método de trabalho é baseado na tese de doutorado idealizada por um ex-professor da Engenharia Sanitária e Ambiental da UFSC, chamado de Pedagogia do Amor (SILVA, 1998).

Os encontros eram realizados com frequência semanal, nas terças-feiras, das $12 \mathrm{~h}$ às $13 \mathrm{~h}$ na escola. Seu tema principal era a aplicação da Educação Ambiental ligada ao conceito de Economia Solidária. Algumas práticas, como a utilização do bastão da fala, as rodas de conversa, passagens de documentários, visitas em salas de aula, com falas das crianças, para estimular o pensamento e a habilidade de oratória (exemplificado na figura 2), foram utilizadas a fim de facilitar a compreensão e comunicação entre todos. Como uma forma pontual de trabalhar a economia circular e solidária, realizaram-se oficinas além dos horários usuais, cujos materiais usados eram constituídos de resíduos recicláveis, objetos em desuso e/ou materiais artísticos. 
Inserindo o conceito lixo zero e a economia sustentável em escolas públicas de Florianópolis

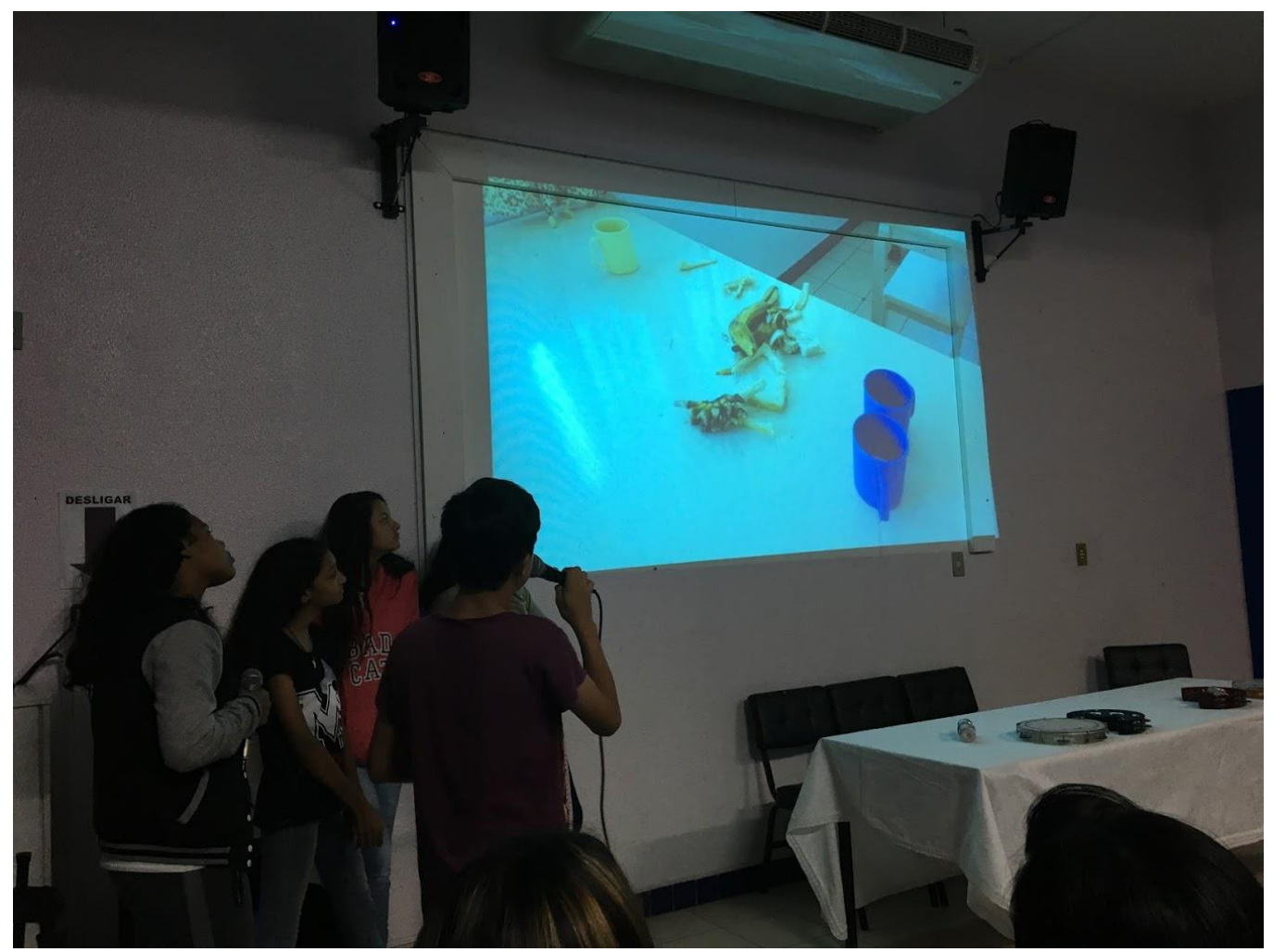

Figura 2 - Apresentação do Coletivo Lixo Zero na Conferência da Sustentabilidade na escola. Fonte: Registrado pelos autores, 2018.

\section{CONQUISTAS E DESAFIOS}

\section{Oficina de minhocário}

Em um dos encontros do coletivo, debateu-se sobre a utilização de minhocários, seus objetivos, benefícios e a metodologia de construção. Junto à teoria, foram feitos três minhocários modelos, que foram entregues à cozinha do Conselho de Moradores do Saco Grande II (responsável por fazer almoço todos os dias às crianças da comunidade), situado em frente à escola, de maneira a apoiar na separação dos orgânicos.

\section{Implementação da horta escolar}

A oficina da horta (Figura 3) possibilitou que os alunos pudessem observar o crescimento das plantas com o passar do tempo. Membros do projeto Mãos à Horta! (NEAmb/UFSC) ajudaram no processo de plantação. Membros do projeto Bioconstrução (NEAmb/UFSC) ajudaram a montar uma barreira entre a terra e o cimento, feita de bambu, para demarcar a área. Assim, foram plantados temperos, chás, verduras e legumes. Foram escolhidas duplas de alunos para regar as plantas todos os dias, cada uma com seu respectivo dia. Foi observado que algumas 
Inserindo o conceito lixo zero e a economia sustentável em escolas públicas de Florianópolis

das duplas, frequentemente, esqueciam de fazê-lo. Por isso, em épocas de pouca chuva, notou-se que as plantas estavam bastante secas. Felizmente, a grande maioria sobreviveu e cresceu saudavelmente. Os alunos puderam levar algumas das ervas e vegetais produzidos, bem como distribuí-los para professores e funcionários.

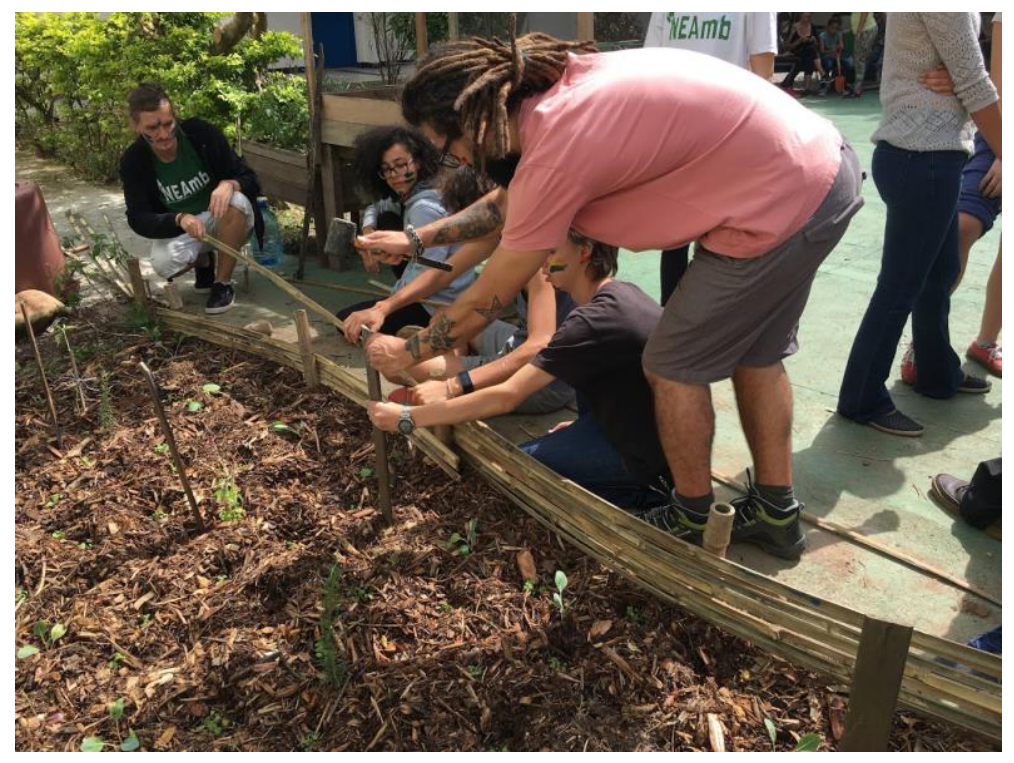

Figura 3 - Mutirão para construção da horta.

Fonte: Registrado pelos autores, 2017

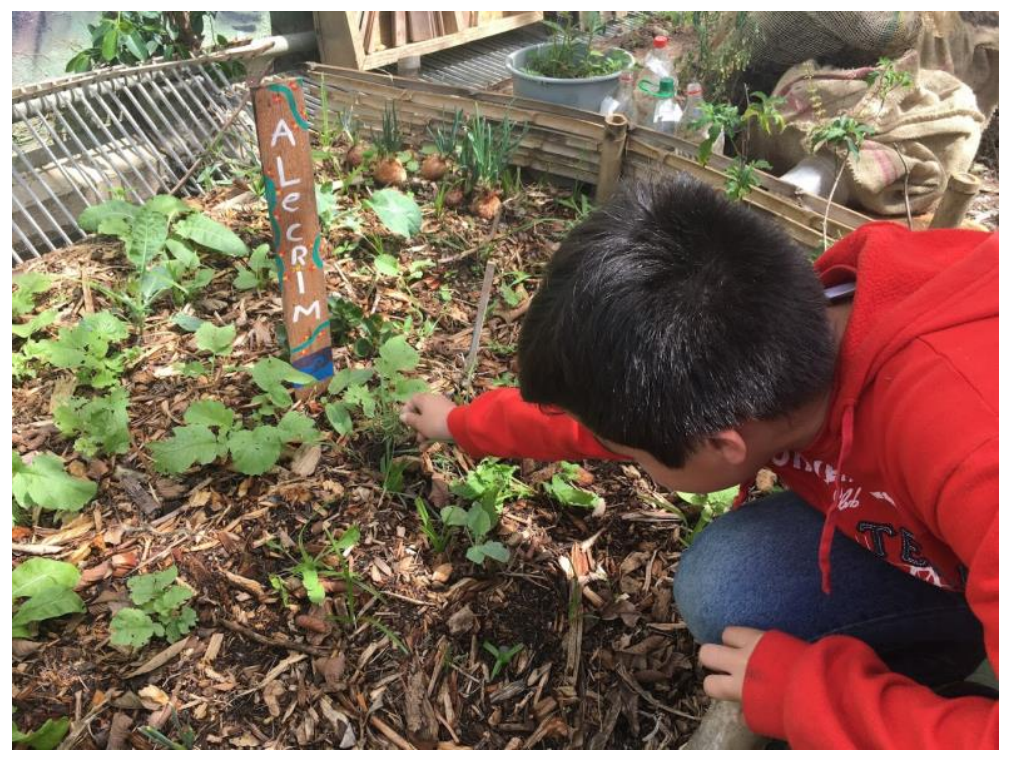

Figura 4 - Manutenção da horta.

Fonte: Registrado pelos autores, 2017 
Inserindo o conceito lixo zero e a economia sustentável em escolas públicas de Florianópolis

\section{Oficina de eco-cadernos}

Caixas para o recolhimento de papel já utilizado foram distribuídas nas salas da escola. Assim, grandes quantidades de papel e rascunho foram acumuladas. Com a colaboração da Sala Verde da UFSC, que emprestou os instrumentos e materiais necessários, foi realizada uma oficina de eco-cadernos a fim de se utilizar os papéis acumulados. Muitos alunos necessitaram de ajuda para colocar as espirais dos cadernos, o que dificultou a sua elaboração. Como essa é uma atividade que exige bastante paciência, alguns alunos deixaram a oficina sem finalizar os seus ecocadernos. Apesar disso muitos saíram satisfeitos e ainda pediram para que repetíssemos a oficina em outro momento.

\section{Oficina de papel reciclado e origami}

Com o auxílio da artesã Silvia Sandri (polpa papel), os membros do projeto foram capacitados para a execução da oficina de papel reciclável. Os papéis utilizados foram os acumulados nas caixas de arrecadação. Já a oficina de origami, foi realizada por uma integrante do NEAmb, que ensinou uma alternativa para a reutilização de papel. Os alunos mostraram grande interesse pelo processo de produção de papel reciclável (figura 5) e a oficina foi finalizada com êxito. Alguns papéis reciclados foram usados posteriormente como crachás de identificação e outros como capa de eco-cadernos.

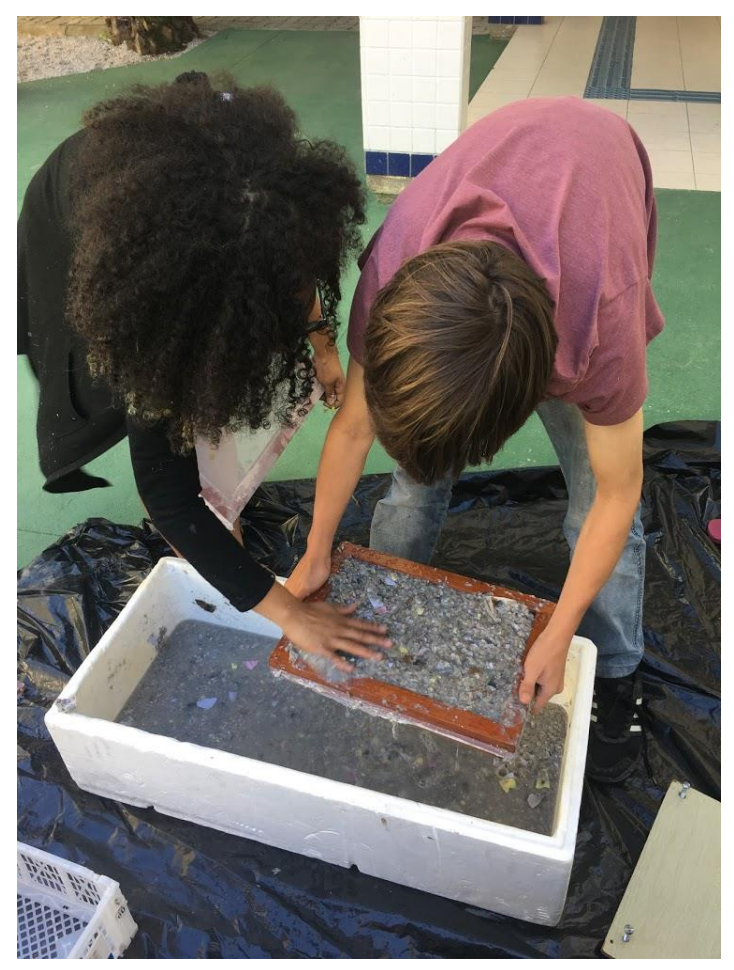

Figura 5 - Oficina de Reciclagem de Papel. Fonte: Registrado pelos autores, 2017 
Inserindo o conceito lixo zero e a economia sustentável em escolas públicas de Florianópolis

\section{Oficina de carteira e estojo com caixa de leite}

Essa oficina teve como objetivo ensinar os alunos a confeccionar objetos úteis no dia-adia a partir de materiais que antes iriam para o lixo. Os membros do NEAmb ministraram a oficina e cada participante colaborou trazendo caixas de leite. Alguns alunos conseguiram criar os seus produtos, porém outros não alcançaram o resultado esperado, já que a confecção exige bastante técnica, sendo um desafio para os alunos mais novos.

\section{Oficina de brincos e colares com material reutilizado}

A oficina capacitou os alunos a fazer criações de brincos e colares a partir de embalagens de papelão e retalhos de tecido que seriam descartados(figura 6). Além dos participantes do Coletivo Lixo Zero, outros alunos, ao passarem ao lado do local da oficina, mostraram interesse e se juntaram ao grupo sem hesitar. Os brincos e colares seriam vendidos posteriormente na feira de economia solidária, mas, como a produção foi grande, vários alunos puderam presentear seus familiares e a si mesmos com o artesanato. A oficina foi um sucesso e os resultados alcançados ultrapassaram as expectativas.

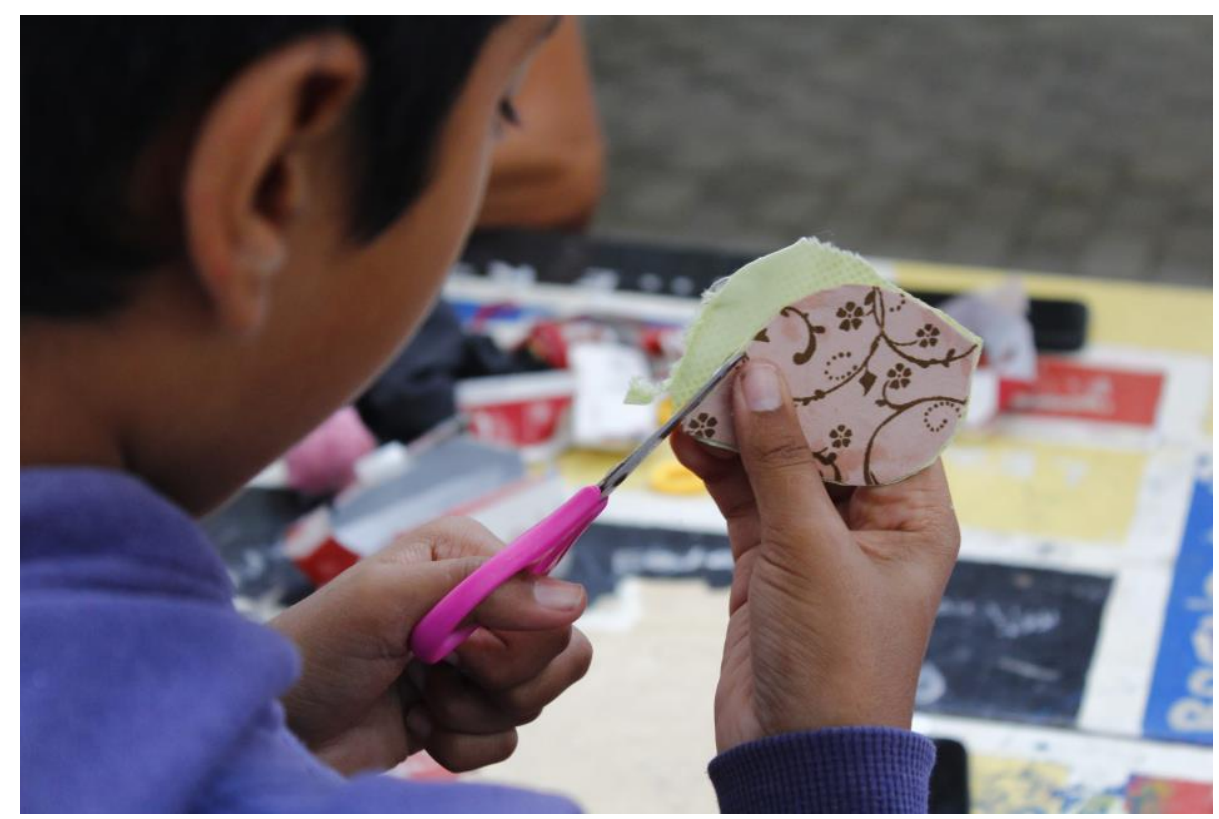

Figura 6 - Oficina de brincos.

Fonte: Registrado pelos autores, 2017.

\section{Oficina de customização de camisetas usadas}

A finalidade dessa oficina foi mostrar aos alunos a possibilidade de criação de uma peça de roupa autêntica a partir de camisetas que estavam em desuso. Cada aluno ficou responsável por trazer uma camiseta inutilizada, para realizar a sua customização. Foram utilizados materiais 
Inserindo o conceito lixo zero e a economia sustentável em escolas públicas de Florianópolis

como tintas, tesouras, retalhos e cordas. As criações ficaram excelentes e os alunos concluíram as oficinas muito satisfeitos.

\section{Feirinha Solidária}

Ao final do ano letivo, foi realizada uma feira nas proximidades da escola Donícia, onde foram vendidos produtos reciclados e reutilizados pelos alunos: brincos, cadernos, suco (servido em um copo reutilizável) e bolos. Antes da feira, ocorreu mais um último encontro, dentro da escola, especificamente para produção em conjunto. Foi um sucesso. Muitas pessoas que passavam na rua pararam para observar e conversar. As crianças explicavam todo o porquê (mostrando fixação do conhecimento obtido com o projeto) e as pessoas demonstravam interesse. Mesmo tendo preços baixos (brincos custavam $\mathrm{R} \$ 2,50$ e cadernos $\mathrm{R} \$ 5$ ), gerou-se uma renda bruta de $\mathrm{R} \$ 80$.

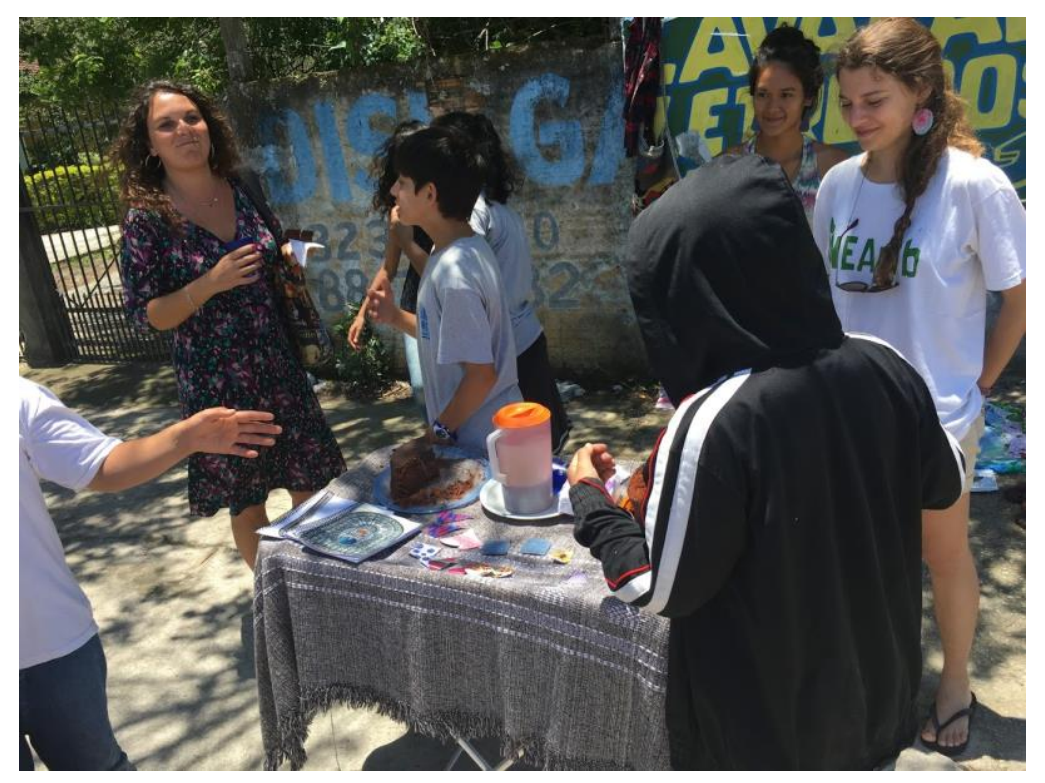

Figura 7 - Feirinha Solidária.

Fonte: Registrado pelos autores, 2017. 
Inserindo o conceito lixo zero e a economia sustentável em escolas públicas de Florianópolis

Chegando ao final do ano, concluiu-se que, apesar de toda a ação ter sido muito efetiva, a escola não daria seguimento, de forma independente, às ações propostas pelo projeto. Assim, concluiu-se que uma nova proposta deveria ser feita para o ano de 2018. Um novo projeto foi escrito e aceito: "Promovendo a economia circular e solidária a partir do conceito Lixo Zero Ano II’. Em 2018, propõe-se trabalhar conjuntamente ao corpo docente para inserir a Educação Ambiental no Plano Político Pedagógico da escola, paralelamente às ações semelhantes às realizadas em 2017.

\section{CONSIDERAÇÕES FINAIS}

Visto que o projeto foi uma continuação de outro iniciado anteriormente na escola, não se encontrou grande dificuldade para o contato entre bolsista/voluntários e comunidade escolar. O Coletivo já tinha sido iniciado no final de 2016 e foi, ao longo do tempo, ganhando mais espaço.

Ressalta-se a grande importância do tripé Ensino, Pesquisa e Extensão para a UFSC, de maneira que estes três itens estimulam uma formação completa aos estudantes. Os editais de Extensão possibilitaram, desde 2015 até 2018, que diversos bolsistas atuassem na ideia de levar a consciência Lixo Zero para escolas públicas. É inegável a experiência obtida: habilidade de liderança; capacitação como educadores ambientais; interação com comunidades carentes; desenvolvimento de comunicação e empatia, etc.

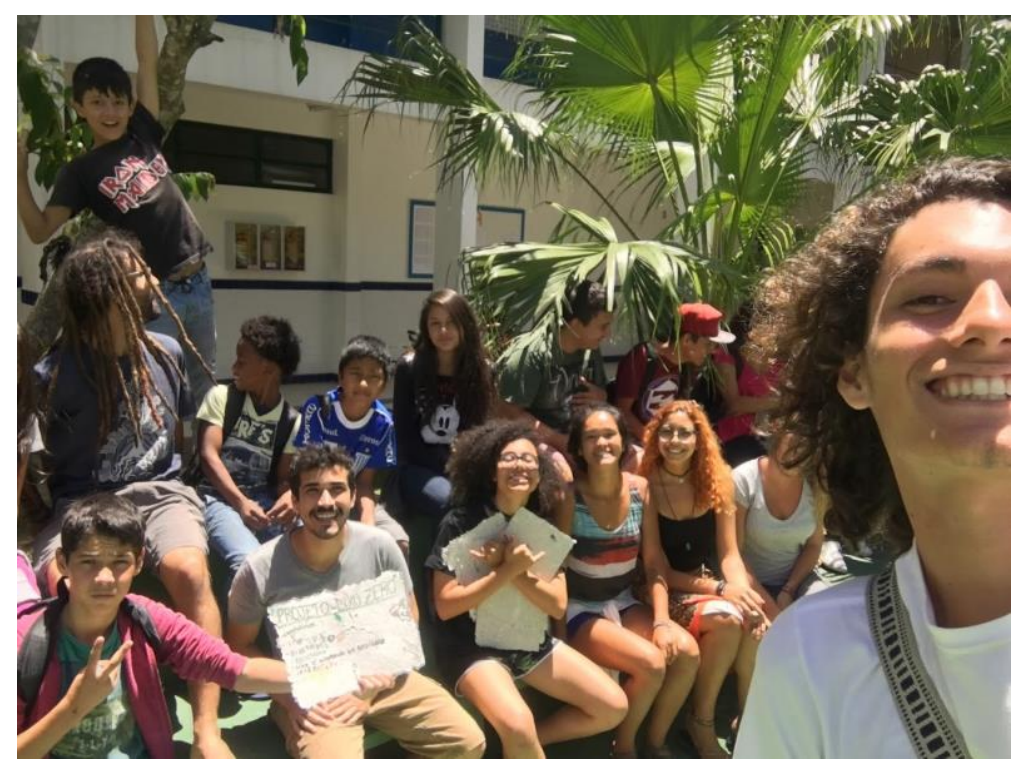

Figura 8 - Encontro pós produção de papel reciclado. Fonte: Registrado pelos autores, 2017. 


\section{REFERÊNCIAS}

ABRELPE, ASSOCIAÇÃO BRASILEIRA DAS EMPRESAS DE LIMPEZA PÚBLICA E RESÍDUOS ESPECIAIS. Panorama dos resíduos sólidos no Brasil, 2015. Disponível em: <http://www.abrelpe.org.br/Panorama/panorama2015.pdf>. Acesso em 23/05/2018.

ELLEN MACARTHUR FOUNDATION. Economia circular. 2017. Disponível em https://www.ellenmacarthurfoundation.org/pt/economia-circular-1/conceito. Acesso em $12 / 07 / 2018$

INSTITUTO LIXO ZERO. Conceito Lixo Zero. 2018. Disponível em: http://ilzb.org/conceito-lixo-zero/. Acesso em 19/05/2018.

MARSHALL, Rachael E.; FARAHBAKHSH, Khosrow. Systems approaches to integrated solid waste management in developing countries. Waste Management, v. 33, n. 4, p. 988-1003, 2013. Disponível em: $<$ http://dx.doi.org/10.1016/j.wasman.2012.12.023 >. Acesso em 23/05/2018

RAZETO, Luis. Los Caminos de la Economía de Solidaridad. Buenos Aires: LUMENHVMANITAS, 1997.

SILVA, D. J. da . Uma abordagem cognitiva ao planejamento Estratégico do Desenvolvimento Sustentável. Florianópolis: Tese de Doutorado (Programa de Pós-Graduação em Engenharia de Produção) da Universidade Federal de Santa Catarina, 1998.

VASCONCELOS, Luiz Gabriel Catoira de. DESAFIO LIXO ZERO : GESTÃO DE RESÍDUOS SÓLIDOS COMO OPORTUNIDADE DE EDUCAÇÃO AMBIENTAL E GOVERNANÇA NO COLÉGIO DE APLICAÇÃO DA UFSC / Luiz Gabriel Catoira de Vasconcelos ; orientador, Armando Borges de Castilhos Jr. ; coorientadora, Josalba Ramalho Vieira. - Florianópolis, SC, 2015. 140 p.

WILSON, David C. Development drivers for waste management. Waste management \& research : the journal of the International Solid Wastes and Public Cleansing Association, ISWA, v. 25, n. 3, p. 198-207, 2007. Disponível em: <http://wmr.sagepub.com/cgi/doi/10.1177/0734242X07079149>. Acesso em 23/05/2018

Recebido em: 25/05/2018

Aceito em: 30/07/2018 